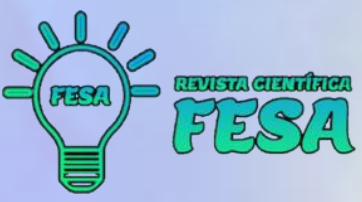

\title{
A INTERNACIONALIZAÇÃO DO CURRÍCULO DA EDUCAÇÃO SUPERIOR À EDUCAÇÃO BÁSICA: UMA REFLEXÃO BIBLIOGRÁFICA SOBRE O TEMA
}

\author{
Homero Alberto Gomes da Silva ${ }^{1}$ \\ Amanda Ribeiro Vieira ${ }^{2}$
}

\begin{abstract}
RESUMO
Este trabalho resulta de pesquisa em desenvolvimento no programa de Mestrado em Educação Profissional Tecnológica no Instituto Federal de São Paulo - campus Sertãozinho que tem por objetivos analisar as estratégias de internacionalização do Instituto Federal de Educação, Ciências e Tecnologia de São Paulo. Como recorte para este artigo, pretende-se fazer uma análise das influências e os movimentos da Internacionalização do Currículo da Educação Superior e suas influências sobre o Currículo da Educação Básica. No texto, apresento e exploro, com base em pesquisas já realizadas, um conjunto de aspectos conceituais e outros elementos de contextualização da internacionalização do Currículo da Educação Superior com o propósito de entender como este movimento influenciam a internacionalização do Currículo da Educação Básica. Como se sabe, o discurso da educação global é propagado pelas agências de desenvolvimento transnacionais como Unesco, Banco Mundial e OCDE que visa fortalecer os projetos da Agenda Estruturada para a Educação Global. Trabalha-se com os procedimentos metodológicos usualmente utilizados em investigação do tipo descritivo-exploratórias, com base em textos de artigos publicados, livros, dissertações e teses que exploram este tema de forma direta e indiretamente. No artigo, apresenta-se, incialmente, algumas definições conceituais no que tange a Internacionalização do Currículo. Numa segunda parte, situa-se os contextos nos quais se insere a educação internacional superior e seus movimentos em relação à internacionalização do Currículo da Educação Básica.
\end{abstract}

Palavras-chave: Currículo. Internacionalização. Educação Superior. Educação Básica.

\begin{abstract}
This work is the result of research in development in the Master's program in Professional Technological Education at the Federal Institute of São Paulo - Sertãozinho campus, which aims to analyze the internationalization strategies of the Federal Institute of Education, Science and Technology of São Paulo. As an outline for this article, we intend to analyze the influences and movements of the Internationalization of the Higher Education Curriculum and its influences on the Basic Education Curriculum. In the text, I present and explore, based on research already carried out, a set of conceptual aspects and other contextualization elements of the internationalization of the Higher Education Curriculum in order to understand how this movement influences the internationalization of the Basic Education Curriculum. As is well known, the global education discourse is propagated by transnational development agencies such as UNESCO, the World Bank and the OECD, which aim to strengthen the projects of the Structured Agenda for Global Education. It works with the methodological procedures usually used in descriptive-exploratory research, based on texts from published articles, books, dissertations and theses that explore this theme directly and indirectly. The article initially presents some conceptual definitions regarding the Internationalization of the Curriculum. The second part presents the contexts in which international higher education is inserted and its movements in relation to the internationalization of the Basic Education Curriculum.
\end{abstract}

${ }^{1}$ Bacharel em direito, licenciado em letras e Pedagogia, mestrando pelo IFSP. E-mail: homgomes@yahoo.com.br

${ }^{2}$ Bacharel, mestre e doutora em Administração pela USP. Professora do Instituto Federal de São Paulo, Campus Sorocaba. E-mail: avieira@ifsp.edu.br 


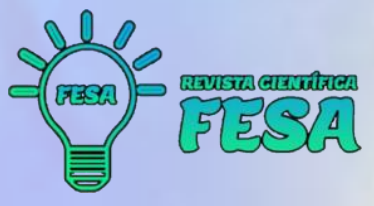

Keywords: Curriculum. Internationalization. College Education. Basic Education.

\section{RESUMEN}

Este trabajo es el resultado de la investigación en desarrollo en el programa de Maestría en Educación Profesional Tecnológica del Instituto Federal de São Paulo - Campus Sertãozinho que tiene como objetivo analizar las estrategias de internacionalización del Instituto Federal de Educación, Ciencia y Tecnología de São Paulo. Como recorte para este artículo, pretendemos hacer un análisis de las influencias y movimientos de la Internacionalización del Currículo de Educación Superior y sus influencias en el Currículo de Educación Básica. En el texto, presento y exploro, a partir de investigaciones ya realizadas, un conjunto de aspectos conceptuales y otros elementos de contextualización de la internacionalización del Currículo de Educación Superior con el propósito de entender cómo este movimiento influye en la internacionalización del Currículo de Educación Básica. Como sabemos, el discurso de la educación global es propagado por agencias transnacionales de desarrollo como la UNESCO, el Banco Mundial y la OCDE, que tiene como objetivo fortalecer los proyectos de la Agenda Estructurada para la Educación Global. Trabajamos con los procedimientos metodológicos generalmente utilizados en la investigación descriptivo-exploratoria, basados en textos de artículos publicados, libros, disertaciones y tesis que exploran este tema directa e indirectamente. En el artículo se presentan inicialmente algunas definiciones conceptuales relativas a la Internacionalización del Currículo. En una segunda parte, los contextos en los que se sitúa la educación superior internacional y sus movimientos en relación con la internacionalización del Currículo de Educación Básica.

Palabras clave: Currículo. Internacionalización. Educación Superior. Educación Básica.

\section{INTRODUÇÃO}

Este texto é resultado de pesquisa realizada no mestrado em fase de conclusão (2018-2021) no Instituto Federal de São Paulo (IFSP), que tem por objetivo analisar as estratégias de internacionalização do IFSP a partir de 2008, ano da instituição da "Rede Federal de Educação" até os dias atuais.

Como delimitação da pesquisa mais ampla, estrutura-se o presente artigo no qual se apresenta e discute um conjunto de definições do que vem a ser a Internacionalização do Currículo que é usado e aplicado na Educação Superior, e como esta influencia a formulação de políticas públicas voltadas a internacionalização do Currículo da Educação Básica.

Segundo Thiessen (2018/2919) não há muita literatura que discorra sobre a internacionalização do Currículo da Educação Básica na América Latina comparando com as inúmeras literaturas que tratam da internacionalização do Currículo da Educação Superior nesta mesma região geográfica. Embora, nos países ricos e industrializados afirmam os pesquisadores (KALOYIANNAKKI; KAZAMIAS, 2012), o tema da internacionalização da Educação Básica já é discutido e desenvolvido desde o início do século XIX, e veio se fortalecendo através dos anos devido as nações centrais terem tido experiências positivas com 


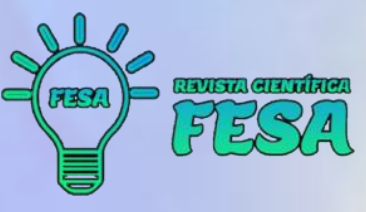

internacionalização dos seus sistemas educacionais para o fortalecimento, o desenvolvimento, as riquezas e domínios que estes países conseguiram em virtude de uma educação que partisse do local ao global.

Trata-se de uma pesquisa exploratória de base empírica histórica que tem como alusão e fontes principais outros artigos científicos, e projetos transnacionais desenvolvidos pelas nações do Norte (países ricos e industrializado) por meio de suas organizações transnacionais como Unesco, Banco Mundial, Unicef e OCDE na busca de estruturar uma agenda global para a Educação Superior e a Educação Básica.

\section{A INTERNACIONALIZAÇÃO DO CURRÍCULO}

O discurso educacional global promovido pelo UNICEF, Banco Mundial e OCDE determina uma Agenda Educacional Global Estruturada para uma convergência internacional curricular para o desenvolvimento internacional das nações do Sul' (DALE, 2002; 2010 BEECH, 2006b; COWEN, 1994). Ainda segundo Beech (2006):

As organizações como a Unesco, OCDE e Banco Mundial foram criadas para a reconstrução da Europa depois da Segunda Guerra Mundial. Porém como essa função tornou-se redundante nas décadas de 1950 e 1960 o trabalho dessas agências dirigiu-se para o desenvolvimento do mundo. (BEECH, p.8, 2006).

Vários são os papéis dessas agências internacionais no processo de desenvolvimento de vários tipos de políticas públicas dos Estados-nações do Sul a partir de 1950 e 1960, porém, far-se-á um recorte no que tange a Educação Formal que é de grande interesse para estes organismos transnacionais. Conforme afirma Beech (2012, p. 419), "cada uma destas instituições tem uma visão depurada para os fins da Educação Formal”.

Beech (2012) discorre que a UNESCO ${ }^{4}$ tem uma visão do desenvolvimento humano dos povos através da educação formal, o Banco Mundial declara que o seu "objetivo fundamental com a educação formal é para o

\footnotetext{
${ }^{3}$ Termo usado pelos países ricos que classificam os países pobres e em desenvolvimento, mesmo que suas localizações não estejam no Sul.

${ }^{4}$ A Organização das Nações Unidas para a Educação, a Ciência e a Cultura.
} 
desenvolvimento econômico para reduzir a pobreza e melhorar o padrão de vida" (BANCO MUNDIAL, 1995, p. 21).

Já o papel da $\mathrm{OCDE}^{5}$ é buscar, promover e balancear certos valores, regras e políticas universais para a Educação Formal propostos pela Unesco e o Banco Mundial para as políticas públicas na educação formal entre os Estados membros e não membros desses organismos (PAPADOPOULOS, 1994). Assim sendo, Beech (2012, p. 418) afirma que "a transferência educacional de ponta é um dos principais papéis assumidos publicamente pela UNESCO, pelo Banco Mundial e pela OCDE".

Nesse contexto, as nações em desenvolvimento e pobres do Sul sofrem grande influência destes organismos internacionais que têm como seus gestores as nações do Norte na formulação e reformulação de suas políticas públicas em geral, e principalmente para a Educação. Porquanto, Thiesen (2017), embasado em vários pesquisados na área de Educação Comparada e Internacional como Knight (1995, 2004, 2008, 2012), De Wit (2011, 2013), Leask (2015), Altbach (2001, 2006), Altbach e Knight (2007), Teichler (2004) e Belen e Jones (2015), afirma que será através da convergência internacional do Currículo que o objetivo da UNESCO, Banco Mundial e OCDE para a Agenda da Educação Global Estruturada será atingido.

Logo, no que tange ao currículo, tal como é apresentado hoje e como uma das ferramentas primordiais para o desenvolvimento internacional pela educação, é importante conhecer sua origem e o seu papel formador na educação formal.

Historicamente, o currículo aparece como um objeto específico de estudo em pesquisas nos EUA na década de 1920, embora, já tenha sido exposto como título do livro de Bobitt em 1918, The Curriculum, afirma Silva (1999). O autor ainda discorre que nesta época "o currículo é visto como um processo de racionalização de resultados educacionais, cuidadosa e rigorosamente especificados e medidos" (SILVA, 1999, p. 12).

Assim sendo, neste parâmetro de uma já suposta teorização curricular, observa-se que o currículo tem uma função específica de formação do indivíduo para um fim específico dentro de um recorte educacional. O que foi

${ }^{5}$ Organização para a Cooperação e Desenvolvimento Econômico. 


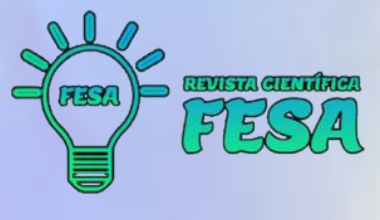

discursivamente apresentado por Bobitt como currículo, vem a ser aquilo que é usado hoje nas instituições educacionais, e que é visto como uma ferramenta de formação humana dentro da Educação Formal tanto por professores como por alunos (SILVA, 1999).

Entretanto, não é fácil se ter uma teoria precisa, única, atual e definitiva do currículo como afirma vários pesquisadores do tema currículo na educação, Silva (1999), Goodson (1995), Sacristan (2000), Apple (1996), Forquin (1993), Giroux (2003).

De fato, as diferentes teorias do currículo enfrentam em si o mesmo dilema da pergunta "o quê?" deveria ser ensinado em detrimento do que deixou de ser.

Silva (1999) elenca as perspectivas envolvidas nas teorias críticas e póscríticas dos currículos do que diz respeito a resposta sobre "o quê ensinar" e qual o destino do/a estudante que segue este ou aquele currículo, o autor discorre:

\footnotetext{
O currículo é sempre um resultado de uma seleção, de um universo mais amplo de conhecimentos e saberes seleciona-se aquela parte que vai constituir, precisamente, o currículo. As teorias do currículo, tendo decididos quais conhecimentos devem ser selecionados, buscam justificar por que "esses conhecimentos" e não "aqueles" devem ser selecionados. Nas teorias do currículo, entretanto, a pergunta "o quê" nunca está separada de outra importante pergunta "o que elas ou eles devem ser?", ou melhor, "o que eles ou elas devem se tornar?". Afinal, um currículo busca precisamente modificar as pessoas que vão "seguir" aquele currículo. (SILVA, p. 15, 1999).
}

Então, nessa perspectiva transformadora das políticas públicas em todas as suas áreas, principalmente na Educação, almeja-se compreender o poder que a globalização e a internacionalização da educação formal têm sobre as configurações e reconfigurações curriculares da Educação Superior e, consequentemente, o que recai sobre a Educação Básica.

Em decorrência do exposto, é preciso entender os movimentos de internacionalização da educação e por conseguinte do currículo que ocorreram nessas últimas duas décadas.

Um dos mais importantes movimentos de internacionalização da educação que ocorre nesta fase contemporânea da globalização é o "Processo de Bolonha". No ano de 1999, na cidade de Bolonha na Itália, fora assinado pelos 27 países membros da União Europeia o tratado europeu de restruturação e 
convergência curricular da Educação Superior Europeia, neste período, dava-se início a uniformidade educacional e curricular dos Estados signatários deste bloco econômico (DIAS SOBRINHO, 2005; PEREIRA, 2011).

$\mathrm{Na}$ ocasião, fora determinado que em 2010 deveria estar concretizado 0 Espaço Europeu de Educação Superior (EEES) no quais as instituições de ensino superior dos países signatários do Processo de Bolonha deveriam ter uma convergência curricular para a formação do cidadão e trabalhador europeu, (U.E $\left.{ }^{6}, 2000\right)$.

A Cúpula de Lisboa, que aconteceu na cidade de Lisboa no ano de 2000, que ratifica a concretização do discurso da UNESCO, do Banco Mundial e da OCDE em propagar uma Agenda Estruturada para a Educação Global. Deste modo, o passo seguinte, depois da estruturação do Espaço Europeu de Educação Superior em (EEES, 2010) era o de influenciar as demais nações para que elas aderissem e aceitassem o Processo de Bolonha (UNIÃO EUROPEIA, 2000).

Em 1999 houve a adesão de 27 países europeus a este tratado. Hoje, haja visto, o sucesso do EEES na União Europeia são 48 países signatários. De acordo com a Cúpula de Lisboa de 2000, depois da efetivação do Espaço Europeu de Educação Superior no ano de 2010, o Processo de Bolonha deveria ser adotados por todos os países da União Europeia, e ser também levado aqueles que sofreram influências da colonização europeia (UNIÃO EUROPEIA, 2000).

Diante disso, no ano de 2000 na cidade de Lisboa em Portugal, ocorreu uma conferência europeia internacional denominada "A Estratégia de Lisboa" que tratava do alcance do Processo de Bolonha através do EEES, este acontecimento afirmava que nenhuma economia mundial deveria ficar de fora do alcance da influência da Educação Superior europeia (UNIÃO EUROPEIA, 2000, p.2).

Sendo o Brasil um dos países mais atuantes do MERCOSUL, a União Europeia tem bastante interesse em entrar e implantar na América do Sul as diretrizes do EEES ${ }^{7}$ para as disseminações de suas políticas voltadas a Educação Superior e sucessivamente na Educação Básica, (U.E, 2000).

\footnotetext{
${ }^{6}$ União Europeia - Cúpula de Lisboa 2000.

${ }^{7}$ Espaço Europeu de Educação Superior.
} 


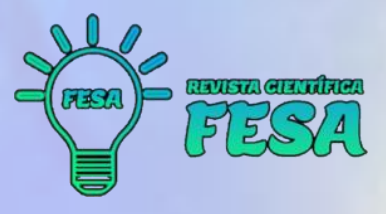

Devido sua dependência social-histórica da Europa, o Brasil se abre ao Processo de Bolonha, não só, ao que culmina a Educação Superior, mas também, no que tange a educação básica. Assim, segundo Rossato (2011), constata-se como o Processo de Bolonha se manifesta no Brasil e quais são suas tendências supranacionais em nossa nação. Este autor declara que:

\begin{abstract}
A universidade brasileira manifesta alguns claros sinais de novas tendências organizacionais e institucionais a partir do início da última década do século XX. As políticas públicas no Brasil, os debates de organismos representativos tanto do Estado como de universidades e outras organizações têm sentido as consequências do Processo de Bolonha e as discussões têm se aprofundado (ROSSATO, p. 182, 2011).
\end{abstract}

Rossato (2011) ainda afirma que:

No contexto da globalização e do neoliberalismo, estes obrigaram as IES a uma abertura do mundo do capital e que o conhecimento passa a ser um produto negociável, a educação passa a ser vista como uma moeda de troca (ROSSATO, p. 186, 2011).

No entendimento da construção do discurso da educação global promovido através da Agenda Estruturada da Educação Universal pela UNESCO, Banco Mundial e OCDE, houve um manifesto dos 430 Reitores das universidades europeias denominada de Carta Magna da "UniversitatumEuropeum" em 18 de setembro de 1988, durante o nono centenário da Universidade de Bolonha Itália, chamada também de Alma Mater de todas as universidades, (U.E, 1988).

Porque a universidade tem um papel fundamental no desenvolvimento social, os reitores europeus entendendo o papel das universidades assinam a Carta Magna, segundo Pereira (2011, p.2), "a Carta Magna estabelece que as universidades deveriam estar, mais do que nunca, conscientes do papel que seriam chamadas a desempenhar numa sociedade cada vez mais internacional e globalizada".

Desse modo, os Reitores das Universidades Federais Brasileiras, reunidos em Salvador, Bahia, em 02 de dezembro de 2006, publicaram um documento intitulado "Manifesto da Universidade Nova pela Restruturação da Educação Superior no Brasil". 


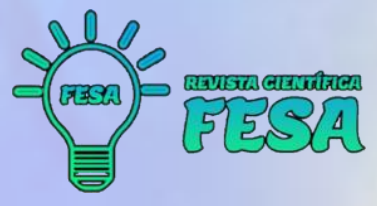

Nesse manifesto foram apontados os problemas das universidades brasileiras nos seus padrões acadêmicos e estruturais e apresentam o Processo de Bolonha como a nova revolução do Ensino Superior para o mundo, (BRASIL, 2006).

Ao se completar o Processo de Bolonha em 2010, unificando o sistema de educação superior do bloco econômico e político da União Europeia, haverá uma incompatibilidade quase completa do modelo brasileiro de formação universitária em relação àquelas vigentes em outras realidades, especialmente dos países desenvolvidos. (UNIÃO EUROPEIA, p.3, 2006)

Este manifesto, em sua constituição, define as estratégias que as Universidades Federais brasileiras deveriam adotar para atingir os fins do discurso global da educação:

\footnotetext{
1 Revisar os currículos e projetos acadêmicos para flexibilizar e racionalizar a formação profissional, proporcionar aos estudantes experiências multi e interdisciplinares;

2 Formular e estimular programas de intercâmbio de âmbito regional, nacional e internacional com mobilidade de estudantes, professores, pesquisadores e servidores técnico-administrativos.

3 Como proposta, destacam a necessidade de a universidade atender as demandas da sociedade do conhecimento e de um mundo do trabalho marcado pela desregulamentação, flexibilidade e imprevisibilidade, adotando na universidade brasileira uma concepção acadêmica pautada em modelos e estudos de graduação de maior abrangência. Também, propõe que se fomentem "iniciativas visando a conceber novas arquiteturas acadêmicas para a Universidade Brasileira, convergindo para o modelo unificado capaz de integrar os diversos regimes curriculares e sistemas de títulos que seja, de preferência, compatível com ou, pelo menos, equivalente aos modelos vigentes nos espaços universitários internacionais, sem, no entanto, significar submissão a nenhum deles (BRASIL, p.4, 2006).
}

Ainda a exemplo da influência do discurso da educação global promovido pelas agências transnacionais UNESCO, Banco Mundial e OCDE, o Manifesto da Universidade Nova no Brasil, transforma o seu discurso em realidade através da Universidade Federal do ABC (BRASIL, 2004).

Assim sendo, Rossato (2011, p. 184) aponta que o "Congresso Nacional aprova o Projeto de Lei 3.962/2004, em junho de 2005, que abriu caminho para a implantação da Nova Universidade Federal" que seria uma das primeiras a adotar os programas do Processo de Bolonha.

No Projeto Pedagógico da UFABC (2004, p.7), Rossato (2011) ainda destaca o ajuste com "a formação de pessoal de nível superior científica a 


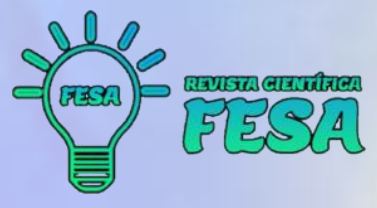

tecnicamente competentes e qualificados para o exercício profissional", ele ainda fala de profissionais consciente dos compromissos éticos e da necessidade da superação das desigualdades sociais e da preservação do meio ambiente". A comissão que criou o Projeto Político Pedagógico da UFABC também determina o que é a universidade. Todo este discurso segundo Rossato está de acordo com os termos do Processo de Bolonha, assim a Universidade Federal do ABC:

\begin{abstract}
Assume compromissos inalienáveis com o progresso do conhecimento racional, a busca da verdade através do método científico, respeitando os princípios éticos subjacentes a toda investigação científica e tecnológica e colocando-os a disponíveis a sociedade. A UFABC está firmemente comprometida com a solução dos problemas sociais e para o desenvolvimento socioeconômico e industrial do país de sua competência e disponibilidade (BRASIL, p.8, 2004).
\end{abstract}

Rossato (2011, p. 184) discorre que "o documento reafirma a necessidade de flexibilização da universidade face à reorganização do mundo do trabalho criando novas exigências de formação". Os articuladores do Projeto pedagógico da Universidade Federal do ABC apresentam de forma clara e explícita a interrelação da formação universitária com o mercado de trabalho:

\begin{abstract}
Para tanto a Universidade tem como expectativa prover cursos que possam proporcionar aos estudantes recursos pedagógicos para a aquisição das ferramentas necessárias a uma atuação ágil e flexível no mercado de trabalho, tornando-os aptos a se adaptarem a diversas atividades do trabalho. Nesse contexto a UFABC deve forjar seus cursos numa concepção de profissionais fundamentada na formação básica densa e na formação profissional plena e não nas especializações restritivas de atuação profissional (BRASIL, p. 9, 2004).
\end{abstract}

Num paralelo aos ciclos de ensino oferecidos pelo Espaço Europeu de Educação, sobretudo, para um aprendizado para a vida, mobilidade estudantil e profissional, a necessidade do mercado de trabalho com o novo perfil profissional, o Projeto pedagógico da UFABC contempla a seguinte estrutura curricular:

1. Ciclos iniciais de três anos, conduzindo ao Bacharelado em Ciência e Tecnologia.

2. Ciclo complementar de um ano para o licenciamento ou bacharelado específico (Física, Química, Matemática, Computação, Biologia) ou Ciclo profissionais de dois anos para engenharia, (BRASIL, 2004, p.12) Obs1: Todos os alunos devem completar o curso de Bacharelado em Ciências e Tecnologia para ingressar em alguma das carreiras de 
bacharelado nas denominações correntes ou licenciatura, (BRASIL, 2004, p. 22)

Obs2: O diploma de Bacharel permitirá aos alunos: a) apresentar-se ao mercado de trabalho como cidadão de nível superior, dotado da visão atualizada da dinâmica científica moderna (BRASIL, p. 9, 2004).

Verifica-se que todo o discurso da educação global da UNESCO, Banco Mundial e OCDE se reverbera sobre a educação superior, sem deixar de lado sua influência e o seu discurso sobre a internacionalização da educação básica, portanto, Thiesen (2019, p. 2) analisa "as implicações dos movimentos de internacionalização curricular no/do Ensino Superior sobre as atuais políticas e reconfigurações curriculares na Educação Básica no Brasil”. Thiesen (2019) amparando em Servilha (2014), Aguiar (2007), Amorim (2012), Nogueira, Aguiar e Ramos (2008), Leask (2009 e 2015), Knight $(2004,2008)$ compreende que:

\begin{abstract}
A internacionalização na Educação Básica como um movimento, ainda inicial, com motivações predominantemente políticas e econômicas, que se fortalece mobilizado por influências de organismos estatais ou privados que operam em instâncias transnacionais. Por diferentes estratégias e instrumentos, induzem Estados nacionais e sistemas educacionais a desencadearem formulação e implantação de reformas em seus currículos de Educação Básica, alcançando inclusive, espaços escolares. São processos e estratégias quem podem incluir desde a formulação de políticas curriculares mais amplas, até reconfigurações, redesenho, adaptações ou adequações curriculares com foco nos conteúdos de conhecimento, nas aprendizagens dos estudantes, na avaliação e nas respectivas metodologias de ensino. Em geral, configuram ações desenvolvidas com perspectivas de alinhamento da educação, do currículo e consequentemente da formação escolar aos padrões do sistema econômico mundial presente (THIESEN, 2019, p. 03).
\end{abstract}

Em vista disso, verifica-se que entre as estratégias de internacionalização da Educação Superior e da Educação Básica, o currículo é o instrumento de entrada da globalização na Educação Formal Básica na escola, e indubitavelmente na formação do aluno.

A educação ocupa lugar central especialmente pela rápida transformação dessa atividade considerada universal, pública e de direito subjetivo, num serviço aos interesses da ordem socioeconômica vigente. Nela, o currículo, território da materialidade na formação escolar, converte-se em estrela de primeira grandeza, dado ser este um dos espaços nos quais as disputas políticas e ideológicas mais se manifestam e onde se constroem os perfis sociais e profissionais tão caros ao mundo do trabalho (THIESEN, p. 330, 2018). 


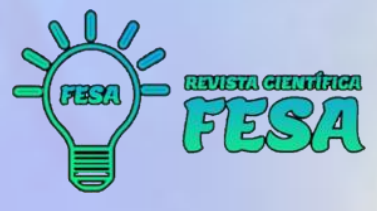

Mediante o exposto, o currículo está entre as estratégias de internacionalização elencadas por Knight (2004), e demonstra ser crucial nas estratégias que internacionalização da Educação Superior, e tem relação as estratégias de internacionalização da Educação Básica.

Finalmente, o que importa é compreender como o fenômeno da internacionalização do Currículo da Educação Superior influencia a configuração e reconfiguração da internacionalização do Currículo da Educação Básica em seus diferentes aspectos e especificidades.

Wielewicki e Oliveira (2010, p.222) assinalam aspectos importantes do contexto de internacionalização do currículo, eles afirmam que:

\begin{abstract}
Em termos educacionais o período ao redor das décadas de 1980 e 1990 é mercado pela eclosão de um movimento de reformas educacionais por todo o mundo, instaurando aquilo que Hargreaves e outros (2002) denominam de "nova ortodoxia oficial", um movimento que é caracterizado pela padronização em torno de políticas de avaliação, financiamento, de formação de professores e de currículo, num processo de nítida sintonia entre tais políticas e a visão de desenvolvimento preconizada por grandes organismos financeiros internacionais como, por exemplo, o Banco Mundial (WIELEWICKI; OLIVEIRA, p.222, 2010).
\end{abstract}

Segundo Thiessen (2019), esses movimentos são, portanto, os que pressionam governos e seus respectivos sistemas educacionais para a formulação de reformas que, em geral, envolvem questões curriculares. Ainda, segundo este autor, os argumentos que justificam iniciativas desta natureza:

\begin{abstract}
Pautam-se, predominantemente, nos ideais de inovação, de melhoria da eficiência e eficácia, com consequente elevação de resultados - todos alinhados aos padrões requeridos ou estabelecidos internacionalmente. Na educação superior, esse movimento é absolutamente evidente e inclusive constitui mote nas universidades e demais instituições de ensino superior brasileira e estrangeiras para a (re)formulação dos chamadas Projetos de Desenvolvimento Institucional (PDI) e Projetos Pedagógicos Institucionais (PPI). Na educação básica, esses requerimentos são traduzidos fundamentalmente na proposição de diretrizes e demais prescrições, por intermédio de projetos de cooperação, pela implantação de mecanismos de avaliação externa no âmbito de sistemas educativos e, ainda, pela regulação e pelo controle, por parte do Estado, via distribuição dos recursos financeiros - estratégias cada vez mais vinculada à verificação de qualidade pelos indicadores de resultados (THIESSEN, p. 5, 2019).
\end{abstract}

Há várias publicações que tratam do tema da internacionalização da educação pautado por organismos internacionais, principalmente, o Banco Mundial 


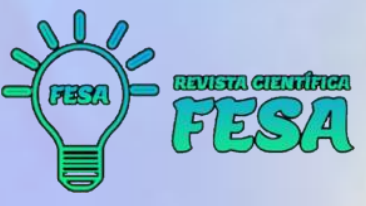

para a área de educação a partir dos anos de 1980. Destaca-se neste momento, o texto do Banco Mundial de 1996, que tem por título "Propriedades e Estratégias para a Educação. Este texto no seu prólogo tem as finalidades e razões bem detalhadas para que a Educação Básica tenha qualidade como foco, afirma Thiessen (2019). Segue na integra parte do texto do documento do Banco Mundial.

\begin{abstract}
É o primeiro exame global do setor de educação publicado pelo Banco desde o documento de políticas sobre educação de 1980 - sintetiza as conclusões das publicações realizadas nos últimos anos. Acrescenta um exame da Educação Secundária que reflete os resultados dos trabalhos em andamento do Departamento de Desenvolvimento Humano do Banco e torna extensivos estes resultados às esferas do financiamento e da gestão setorial. Baseia-se também, consideravelmente, no informe mundial sobre a educação da UNESCO (1993). No informe se delineiam as opções de política que podem adotar os países de baixo e médio ingresso visando fazer frente aos problemas educacionais à medida que avançam para o século XXI (BANCO MUNDIAL, AP. 12, 1996)
\end{abstract}

Thiessen (2019), ainda aponta algumas declarações e movimentos feitos por organismos internacionais igualmente importantes as declarações do Banco Mundial. Entre estes eventos o autor destaca: Jomtien (UNICEF $\left.{ }^{8}, 1990\right)$, Nova Delhi (UNESCO, 1993) e o de Dakar (UNESCO, 2000) entre outros patrocinados pelo $\mathrm{PNUD}^{9}$ e BID ${ }^{10}$. Conforme enfatiza Thiessen (2019), em geral, todos estes documentos têm expressiva repercussão na formulação de políticas curriculares dos sistemas educacionais, especialmente dos países signatários.

Para concluir, o Banco Mundial (2011/2020), lança o programa "Educação para Todos" promovendo reformas nos sistemas de educação dos países criando uma base global de conhecimentos suficientemente forte para liderar as reformas propostas pelo banco. A OCDE cria programas de formulações curriculares de países em desenvolvimento, e dentre tantos, destaque-se o PISA ( Programa Internacional para o Acompanhamento das Aquisições dos Alunos), e vários outros projetos dentro do seu Centro de Pesquisa e Inovação Educacional do qual valha apena destacar o inspirados pela tecnologia, norteados pela pedagogia chamado uma " uma abordagem sistêmica das inovações educacionais de base tecnológica, (OCDE, 2010), o qual vários países em desenvolvimento acoIheram, inclusive o Brasil, comenta Thiessen(2019).

${ }^{8}$ Fundo Internacional de Emergência das Nações Unidas para a Infância.

${ }^{9}$ Programa das Nações Unidas para o Desenvolvimento.

10 Banco Interamericano de Desenvolvimento. 


\section{CONSIDERAÇÕES FINAIS}

A tarefa de pesquisa desenvolvida nesta fase do trabalho admitiu, dentre outros aspectos, a assimilação de exploração de importantes observações conceituais que servem de referência para o entendimento da problemática da Internacionalização do Currículo da Educação Superior à Educação Básica em geral atrelado aos desígnios e orientação das organizações transnacionais como Unicef, Unesco, Banco Mundial e OCDE destas últimas décadas - formulações que também serviram de base para a identificação do discurso de uma Agenda Estruturada para a Educação Global promovido por estes organismos sobre o comando dos países do Norte que veem o Currículo como mecanismo para o desenvolvimento e melhoramento dos países do Sul.

Em parceria a essas abordagens teóricas, que contou com a participação de artigos científicos de outros pesquisadores, também foi possível contextualizar o movimento de Aprendizagem para Todos proposto pelo Banco Mundial, seguido pela UNESCO e OCDE todos com um tipo de abordagem diferente sobre o poder transformador da educação, porém, com o mesmo objetivo que é o processo de internacionalização do Currículo da Educação Básica, assim, como já foi feito com a Educação Superior.

Quanto aos trabalhos científicos identificados nas bases de apoios do que tange a bibliografia estudada o presente artigo, verificou haver evidente predominância de pesquisa sobre a temática desenvolvida pelos países do Norte mantenedores das agências transnacional de desenvolvimento contemplando a internacionalização do currículo como sinônimo de uma educação de qualidade para todos os países signatários destas.

Daí a importância de se explorar com maior detalhamento este fenômeno de internacionalização do currículo tanto para a Educação Superior, como para a Educação Básica para a formação internacional do homem para o mundo trabalho em constante transformação.

Finalmente, vale salientar que não oponente ao trabalho acadêmico de diversos pesquisadores que busca entender como o movimento da internacionalização do currículo poderá influenciar as políticas públicas educacionais de várias nações pobres e em desenvolvimento. Ainda existe um longo trajeto a ser 


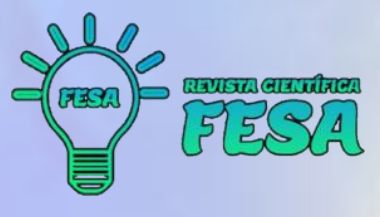

percorrido, sobretudo no que se refere a necessidade de aprofundamento das questões conceituais e das implicações quem a implementação de internacionalização do currículo fornecidas pelas agências transnacionais de desenvolvimento poderão acarretar aos países que nelas se apoiam para formular suas políticas públicas, principalmente as políticas educacionais curriculares.

\section{REFERÊNCIAS BIBLIOGRÁFICAS}

AGUIAR, A.M.S. O recurso às escolas internacionais como estratégia educativa de famílias socialmente favorecidas. 2007. Doutorado em Educação. Faculdade de Educação, Universidade Federal de Minas Gerais, Belo Horizonte, 2007.

AMORIM, M.A. Educação dos Brasileiros e estrangeiros: breve histórico da internacionalização dos estudos no Brasil. Brasilana Journal for Brazilian Studies, London, v.1, n.1, p. 44-65. Set; 2012.

ALTBACH, P. G.; KNIGHT, J. The Internationalization of Higher Education: motivations and realities. Journal of Studies in International Education, v. 11. n. 3/4, p. 290-305, 2007.

ALTBACH, $\mathrm{P}$. Why higher education is not a global commodity. The Chronicle of Higher Education. USA, v. 47, may 2001.

ALTBACH, P. Globalization and the university:R. Realities in na unequal world. J.J.F. Forest and P.G. Altbach (eds), Internatonal Handbook of Higher Education, vol. 1. Dordrecht, The Netherlands, Springer, 121-140. 2006.

ALTBACH, P. Education and neocolonialism. Teachers College Record, v. 72, n. 4, p. 1997.

APPLE, M. Ideologia e currículo. 3.ed. Porto Alegre: Artmed, 2006.

BANCO MUNDIAL. Estratégias 2020 para a educação do grupo Banco Mundial: resumo executivo. Aprendizagem para todos: investir nos conhecimentos e competências das pessoas para promover o desenvolvimento. Washington, DC: Banco Mundial 2011.

BANCO MUNDIAL. Prioridades y estrategias para lá educación: examen del Banco Mundial. Washington, DC: Banco Mundial, 1996.

$\mathrm{BEECH}, \mathrm{J}$. Redefining educational transfer: International agencies and the (re)production of educational ideas. In: SPROGOE, J.; WINTHER-JENSEN, T. (Eds.). Identity, education and citizenship: multiple interrelations. Frankfurt am Main: Peter Lang, 2006b. 


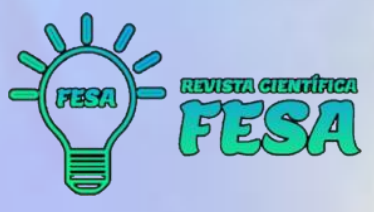

$\mathrm{BEECH}, \mathrm{J}$. The theme of educational transfer in comparative education: a view over time. Research in Comparative and International Education, v. 1, n. 1, p. 2-13, 2006a.

BEECH, J. Quem está passeando pelo jardim global? Agências Educacionais e transferência educacional. IN: : Educação comparada: panorama internacional e perspectivas; volume um / organizado por Robert Cowen, Andreas M. Kazamias e Elaine Ulterhalter. - Brasília: UNESCO, CAPES, 2012, p.413-433.

BEELEN, J.; JONES, E. Redefining internationalization at home. In: The European Higher Education Area: between Critical Reflections and Future Policies. Springer Opeen Cham: Springer, 2015.

BRASIL. Projeto Pedagógica da Universidade Federal do ABC. Disponível em: Acesso em: 18/07/2020.

BRASIL. Instituto Nacional de Estudos e Pesquisas Educacionais Anísio Teixeira. O Pisa e o IDEB, Brasília. DF. Inep, 2016. Disponível em: https://www.gov.br/inep/pt-br/areas-de-atuacao/avaliacao-e-exames-educacionais/pisa acesso em 30 de agosto de 2020.

COWEN, R. Schools and selected aspects of culture from the perspective of comparative education: neither a borrower nor a lender be. In: THOMAS, E. (Ed.). International perspectives on culture and schooling: a symposium proceedings. London: Department of International and Comparative Education, Institute of Education, University of London, 1994.

COWEN,R; KAZAMIAS, A. Criação e recriação de um campo de estudos. IN: Educação comparada: panorama internacional e perspectivas; volume um / organizado por Robert Cowen, Andreas M. Kazamias e Elaine Ulterhalter. - Brasília: UNESCO, CAPES, 2012, p.13-22.

DALE.R. Globalização e Educação: demostrando a existência de uma "Cultura Educacional Mundial Comum" ou localizando uma "Agenda Globalmente Estruturada para a Educação. Campinas: Educ. Soc, vol.25, n. 87, p. 423-460, 2004.

DIAS SOBRINHO, J. O Processo de Bolonha. In: ALMEIDA, M. L. P. de; PEREIRA, E. M. de A.(org.). Universidade contemporânea: políticas do processo de Bolonha. Campinas: Mercado das Letras, 2009. p. 129-152.

DIAS SOBRINHO, J. Dilema da educação superior no mundo globalizado: sociedade do conhecimento ou economia do conhecimento. Casa do Psicólogo, São Paulo, 2005.

DE WIT, H. Internationalization of Higher Education: Nine Misconceptions. International Higher Education, n. 64, Summer, 2011. p. 6-7.

DE WIT, H. Reconsidering the Concept of Internationalization. In: Autoria. International Higher Education. Boston. December, 2013. 


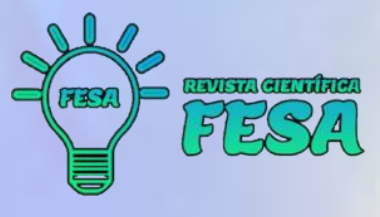

FORQUIN, Jean-Claude. Escola e cultura: as bases sociais e epistemológicas do conhecimento escolar. Tradução: Guacira Lopes Louro. Porto Alegre: Artes Médicas, 1993.

GIROUX, Henry. Os professores como intelectuais - Rumo a uma pedagogia crítica da Aprendizagem. Trad.: Daniel Bueno. Porto Alegre: Artes Médicas, 1997.

GIROUX, Henry. Escola crítica e política cultural. 3. ed. Trad. Dagmar Zibas. São Paulo: Cortez/Autores Associados, 1992. Coleção Polêmicas do nosso tempo.

GOODSON, I. O Currículo: teoria e história, Petrópoles: Vozes, 1995.

KNIGHT, J. Higher education in turmoil: the changing world of internationalization. Rotterdam: Sense Publishers, 2008.

KNIGHT, J. Internationalization remodeled: definition, approaches and rationales. Journal of Studies in International Education, Toronto, v. 8, n. 1. p. 5-31, Mar. 2004. Disponível em: https://journals.sagepub.com/doi. Acesso em: 22 maio 2019.

KNIGHT, J. Student mobility and internationalization: trends and tribulations. Research in Comparative and International Education, v. 7, 1, p. 20-33, 2012. Disponívelem: https://journals.sagepub.com/doi/. Acessoem: 19 maio 2019.

KNIGHT, J. International Education Hubs: Students, talent, knowledgme-inovation models. Springer Netherlands, 2014.-221, 2009.

KNIGHT, J. The Internationalization of Higher Education: complexities and realities. In: TERREFA, Damtew; KNIGHT, Jane. Higher education in Africa: the international dimension. Massachussetts, USA: Boston College, 2008.

LEASK.B. Internationalizing the curriculum. New York: Routledge, 2015.

LEASK.B. Using formal and informal curriculum to improve interections between home and international students. JournalofStudies in InternationaIEducation: v.13, n.2.p.205-221, 2009.

NOGUEIRA, M.A; AGUIAR, A.M.S; RAMOS, V.C.C. Fronteiras desafiadas: a internacionalização das experiências escolares. Educação e Sociedade, Campinas, v. 29, n. 103, p.335-376, maio/ago. 2008.

ONU. Pacto Internacional dos Direitos Econômicos, Sociais e Culturais. * Adotada pela Resolução n.2.200-A (XXI) da Assembléia Geral das Nações Unidas, em 16 de dezembro de 1966 e ratificada pelo Brasil em 24 de janeiro de 1992. Disponível em: https://www.oas.org/dil/port/1966\%20. Acesso em 02/07/2020.

ORGANIZAÇÃO PARA A COOPERAÇÃO E DESENVOLVIMENTO OONERGÉNAASTEÓRCASDOMNDOCONIEMPORÂNEO 


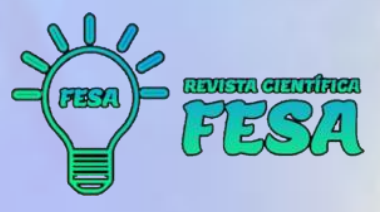

ECONÔMICO. AdvancingNationalStrategies for Financial Education, a joint publicationbyRussia'sG20Presidencyandthe OECD. It is circulated for information to G20 Leaders at their Summit meeting in St-Petersburg on 5-6 September 2005.

OCDE. Inspirados pela tecnologia, norteados pela pedagogia, uma abordagem sistêmica das inovações educacionais de base tecnológica. \{S.I\}: Centro de Pesquisa Educacionais e Inovação, 2010. Disponível em: https://www.oecd.org/education.pdf acesso em 07 de setembro de 2020.

PAPADOPOULOS, G. Education 1960-1990: the OECD perspective. Paris: OECD, 1994.

PEREIRA, E. M. A. (Org.); ALMEIDA, Maria de Lourdes Pinto de (Org.). Reforma universitária e a construção do espaço europeu de educação superior: análise de uma década do Processo de Bolonha. Campinas: Mercado de Letras, 2011

SACRISTÁN, J. G. O currículo: uma reflexão sobre a prática. Porto Alegre: Artmed, 2000

SERVILHA, G.B. A internacionalização do ensino básico, suas motivações. 2014. Dissertação Mestrado - Universidade de São Paulo, São Paulo, 2014.

SILVA JR., J. dos R. Reforma do Estado e da educação no Brasil de FHC. São Paulo: Xamã, 2002.

SILVA, D. H. D. Cooperação internacional em ciência e tecnologia: oportunidades e riscos. Revista Brasileira de Política Internacional, Brasília, v. 50, n. 1, p. 5-28, jan. 2007.

SILVA, T. T. Documentos de Identidade: uma introdução às teorias do currículo. - 3.ed. reimp - Belo Horizonte: Autêntica, 2010.

TEICHLER, Ulrich. The changing debate on internationalization of higher education. HigherEducation, n.48, p 5-46, 2004.

THIESEN, J. S. A Internacionalização do Currículo. In: PACHECO, J. A.; PERALTA, D.A.; THIESEN, J.S.; SCALABRIN,R. (org.) Currículo como pauta contemporânea: formação, avaliação e internacionalização. Braga: Ed. In Line, 2018.

THISEN, J.S. Currículo da Educação Básica Brasileira: convergências com o discurso educacional global em contextos de internacionalização. Revista IberoAmericana de Estudos em Educação, Araraquara, v.14, n.2, p.420-436. 2019.

THIESEN, J.S. Estratégias de Internacionalização da Educação e do Currículo: das universidades aos territórios da Educação Básica. Arquivos Analíticos de Políticas Educativas, 27(59). http://dx.doi.org/10.14507/epaa.27.3622. (2018).

\section{CONMRGÂNDASTECÓRICASDOMNDOCONIEMPORÂNED}


UNESCO. A Declaração de Nova Delhi sobre a Educação Para Todos. Nova Delhi - UNESCO, 1993. Disponível em: https://unesdoc.unesco.org/search/NEXPLORE-3c936057-8cd2-4e27-bee0-3df05a57bf89 - Acesso em 19 de agosto de 2020.

UNESCO. O Marco da Ação de Dakar Educação Para todos: entendendo nosso compromisso coletivo. Dakar: Cúpula Mundial de Educação: 2020.

UNICEF. Brasil. Declaração Mundial sobre Educação Para Todos: Conferência de Jomitien: Unicef, 1990. Disponível em: https://www.unicef.org/brazil/declaracao-mundial-sobre-educacao-para-todos-conferencia-de-jomtien-1990 acesso em 20 de agosto de 2020.

UNIÃO EUROPEIA. O Processo de Bolonha e o Espaço Europeu de Educação. Disponível em: https://ec.europa.eu/education/policies/higher-education/bologna-process-and-european-higher-education-area_pt. Acesso em: 14/7.2020.

WORLD BANK. Priorities and strategies for education: a World Bank sector review. Washington, DC: World Bank, 1995.

WIELEWICK. H.G; OLIVEIRA, M.R. Internacionalização da Educação Superior: Processo de Bolonha. Ensaio, Rio de Janeiro, v. 18, n. 67.p. 215-234, abr./jun.2010. 